\title{
In the Service of Infinite and Glorious Creation: The Nature Writing of Louisa Anne Meredith
}

\author{
Kordula Dunscombe
}

et us strive, dear boy, to comprehend
Our great Creator's might,
Reading NATURE
- that story without an end,
- With minds where inquiry and
tenderness blend,
For our life-long and pure delight.
(Grandmamma's Verse Book for Young Australia p.36)

It is heartening to look back on C19th colonial literature for children and see, amongst the messages of domination, exploitation and general disrespect for the environment, that other paradigms of the land were also offered to child readers.

Louisa Anne Meredith (1812-1895) was an ardent campaigner for the Australian environment, and in particular for its flora and fauna, in an age when the New World was more often considered either a limitless resource, or not worthy of respect. From a viewpoint clearly defined as feminine, and working within the established views and conventions of her time, Meredith managed to offer an alternative to the masculine domination of nature so characteristic of the colonial relationship with the New World. Drawing on all the 'feminine accomplishments' of a middle-class lady, she strove to foster in her readers a multi-dimensional appreciation of the natural world, encompassing emotional, spiritual, ethical, aesthetic, cultural, scientific and practical understandings.

Louisa Meredith was born in 1812 in Birmingham, England. Her interest in the arts was evident from an early age, and while still in her teens she was supporting herself by painting miniatures. As ayoung woman she was active in the cultural life of Birmingham, exhibiting miniatures with the Royal Birmingham Society of Artists and writing poetry and reviews for the Birmingham Journal. In the early 1830 s, she was briefly involved with the Political Union (which became the Chartist Movement in 1837) which advocated social equality and parliamentary reform. Her more liberal views, such as her condemnation of the treatment of convicts, may have had their origins in this early political involvement. On the death of her father in 1835, she took over his position as Corn Inspector for
Birmingham; and in that same year published her first book of poetry and illustrations, Poems. When Meredith married her cousin, Charles Meredith in 1839, she left a well-established career and position in the artistic community of Birmingham to return with him to Australia for a visit that became a life-long stay due to financial misfortune (Ellis 1979).

Meredith's interest in natural history, and in nature as a source for creative activity, was already well developed before her marriage and migration to Australia in 1839. She had published six works in England (1835 to 1839), most in the fashionable genre of the sentimental flower book (Smith 1960, p.225) - a celebration in poetry and prose of picturesque nature, especially flowers and scenery, accompanied by botanical illustrations. The roots of her conservationist outlook are evident in these works, which are of particular interest for their reflections on the worth of developing an enduring love of nature. Meredith argues, in true Romantic fashion, for the unique and inherent value of nature: 'not only ... beautiful, but also ... morally healing and exercising a "beneficent spiritual power over man".' (Pepper 1984, p.80) It is a belief which she applies equally to her 'old friends' in England, and to the unfamiliar nature of Australia.

Meredith arrived in Australia in 1839, spending two years in New South Wales before settling permanently in Tasmania. Despite often adverse conditions (and educating her three children) she continued writing, sketching and painting, finding an endless source of creative inspiration and novel subject matter in the native flora and fauna. In addition to the eight books for a more general audience, she produced four books for children: Loved, and Lost! The true story of a short life (1860), an 'ode' written for her youngest son on the death of a beloved tame parrot; Some of My Bush Friends in Tasmania: Native lowers, berries, and insects drawn from life, illustrated in verse and briefly described (1860), a self-explanatory title pitched at a family audience; Grandmamma's Verse Book for Young Australia (1878), a collection of poems written expressly for the Australian school room, most with some form of native fauna as their subject and respect for nature as their theme; and Tasmanian Friends and Foes, Feathered, Furred and Finned. A family 
chronicle of country life, natural history, and veritable adventure (1880), an ambitious attempt to combine (in narrative form) a survey of Tasmanian fauna and flora with an historical overview of white settlement.

Her Tasmanian works have an increasingly overt conservationist message, as she witnessed the growing detrimental impact of white settlement on the land. After her husband, Charles, became a Member of Parliament in 1855, Meredith was able to broaden her fight for Tasmanian wildlife by encouraging him to introduce several bills, such as that for the protection of the black swan passed in 1860 (Ellis 1979, p. 183-4). She was awarded a government pension in 1884 in recognition of her contribution to Tasmanian culture: she had 'by her writings and paintings rendered considerable services to the cause of Science, Literature and Art in Tasmania.' (Ellis 1979, p.218)

Before discussing Meredith's nature writing, it is worth briefly outlining her definition of the term 'nature'. Any material thing of non-human origin comes under her banner of nature. The term is applied to objects and environments (or settings), but it also names a nonhuman creative force. All the small 'productions' of the material world - flowers, trees, birds, animals, rocks, shells etc. - are seen as part of nature and, at various times, taken as representative of nature as a whole. Nature as environment or setting ranges from the tamed to the wild, encompassing the cottage garden, the pastoral countryside, the semi-inhabited bush, the primeval forest. As non-human productions, natural objects and environments are the manifestations of a creative force. Her reference to nature as 'that story without an end' indicates its endlessly self-renewing, self-perpetuating character and its inherently independent existence.

\section{AUNT LUCY'S SYSTEM}

The last of Meredith's English books, and her first for children, Our Wild Flowers (1839), was an encyclopaedic survey of British wild flowers structured as a series of conversations between Aunt Lucy (Lucy Merton) and her young niece Agnes, and interspersed with poems, illustrations and authorial asides. In this work, through the character of Lucy Merton (who bears a remarkable likeness to the author), Louisa Meredith defines her own identity as an author/artist, and outlines the approach that was to characterise áll her work:

'I am as fond of flowers as any one can be; they are the darlings of Creation in my eyes, yet $I$ can be very happy in my enjoyment of them; can cultivate, admire, examine, and endeavour to imitate their beauty in drawings, without possessing either strictly scientific or classical knowledge to aid me. Suppose you try my system, at least for the present.'

'I will try anything you like, dear Aunt, that will make me know something more about flowers; but as to 'your system,' that's another thing, because, as far as I have seen, it includes painting flowers, which I cannot do, and writing such fables and songs about them as very few people can.'

'At least to your taste, Agnes,' said Aunt Lucy who was by no means vain of her rhymes.

(Our Wild Flowers, p.3)

Aunt Lucy's system champions the amateur pursuit of interests, for both Lucy/author/teacher and Agnes/reader/ student. It eschews 'strictly scientific or classical knowledge' as unnecessary or even irrelevant to an enjoyment of nature (represented here by flowers). Aunt Lucy's 'hobbies' are accepted past-times of the middleclass lady: gardening, nature rambles, natural history, botanical drawing and painting, and writing poetry and prose; they are sufficient for a rewarding intellectual and creative engagement with nature. It is a 'hands on' active response, recommending, by example, a personal engagement with one's subject. It also sets out the parameters within which Meredith felt it appropriate to make her creative endeavours public: the sphere of 'feminine accomplishment' (Greer 1995, p.17) is where she chooses to operate.

Meredith's writing is loaded with an awareness and foregrounding of her less authoritative status as a woman author, and she quite consciously cultivates the authorial persona of accomplished amateur throughout her literary career. Self-deprecating comments abound in her works:

I find that my small story, like its grander relatives in the literary world, is quite incomplete without a few notes...

(Loved, and Lost! p.90) 
As a woman, she clearly took her exclusion from the domain of the expert as a 'given'. Agnes, for example, who shows exceptional sensitivity to and interest in nature, is not even in the running for a scientific career: "It is very probable that her talents may not be such as to make her shine in the world of science as a learned botanist, or a profound astronomer ...' (p.67) As far as Meredith is concerned, the sphere of the amateur is women's intellectual and creative playing field.

Aunt Lucy's rejection of 'strictly scientific or classical knowledge' is a refusal to attempt an unequal participation in the male domain of the expert rather than anti-intellectual. Meredith advocates the acquisition of knowledge in all her books for children; as Aunt Lucy puts it,

'We cannot be too thankful for the blessings of living in an age of such advanced intelligence, nor too persevering in the acquisition of information that will render us worthy members of modern society.'

(p.15)

Aunt Lucy herself is described as 'Loving knowledge for its own sake herself [and] delight[ing] in communicating it to others. '(p.9) Meredith's mannered modesty and selfprofessed amateurism ensures that this love of knowledge never comes across as inappropriate to her female status:

'Careful scientific descriptions of all these creatures have been written by learned naturalists for learned people; the only ground on which there is room for our pens is the familiar everyday knowledge of little habits and peculiarities, which the greatest professors at home can not always observe for themselves.'

(Tasmanian Friends and Foes, p.69)

However, in her frequent and apparently humble 'disclaimers', there is also a thinly disguised critique of the 'expert'. In the one quoted above, for example, she subtly undermines the authority of the 'greatest professors' by implying that they have little first hand knowledge of their subjects.

Her critiques make it clear that, as well as being genderbased, her assumed 'anateurism' entails a well thought out theoretical position on the value of close personal observation and direct experience of one's subject. Meredith's embracing of the amateur is also a philosophical commitment to experience over acquired knowledge. All her works are fuelled by the conviction that it is only through extensive personal contact with one's subject that a deep and comprehensive understanding can be achieved. As one of her characters expresses it: '... talking or reading about beautiful creatures is very different from seeing and knowing them' (Tasmanian Friends and Foes, p. 129).

Aunt Lucy's system contains a subversive element a critique of the male experh in its recognition of the value of the personal and emotional, finding instead strengths in what has traditionally been assigned to women and consigned to the category of 'intellectually inferior' [as opposed to the more 'scientific' male qualities of 'the impersonal, the rational, and the general' (Keller 1985, p.7)].

Meredith's refusal to adopt a position of mastery over nature is evident on a creative, as well as an intellectual, level. Her works are assemblages of different methods prose, poetry, factual description, botanical and decorative drawings - which in combination could approximate the range of nature's varied significances; admissions that nature is not easily captured. Clearly, Meredith found any single approach inadequate to express this range. Frustration with the imperfectness of individual means of expression surfaces on a number of occasions, whether this be a limitation of the medium:

'And now I am puzzled - quite puzzled how to describe to you another of .our native oddities; odder and queerer than you can fancy from any description I have heard Mamma speak of the little English hedgehogs.'

(Tasmonian Friends and Foes, p.55):

a limitation of her abilities in the medium:

I soon relinquished my pencil, and shut my book, half in disgust at my own presumption in attempting for an instant a subject so far beyond my poor abilities [on sketching a group of tree ferns].

(My Home in Tasmania, p. 176); 
or a fundamental 'unrepresentableness' of the subject:

Would that my sketch could be endowed with the fragrance of the glorious flowers it represents ... But even as 'No fine chisel ever yet cut breath,' so may no pencil be gifted to paint perfume... (Some of My Bush Friends in Tasmania, p.53)

Ultimately, it seems that even while it creatively inspires, nature is always beyond representation. Meredith's ambivalence to the whole process of 'trapping nature on paper' is both an admission and a desire that nature cannot be contained, that it is greater than any representation of it.

Delys Bird suggests that the writings of colonial women offer a different potential relationship of colonist to the land:

Constructed from a female space, using what are considered peculiarly feminine forms, colonial women's writings allow for the possibility of a different perception of the landscape; enabling a challenge perhaps to the masculine bush legend; allowing an alternative to the male manipulation of the environment; enacting a response less potentially destructive than is the familiar pattern of fear and fascination, threat and desire that structures those official male accounts of the Australian landscape. Colonial women's writings may thus allow for another view of the new land. (Bird 1989. p. 21-2)

In refusing the kind of domination exercised by the "great men of science and culture', and in subjugating herseif to a nature that can never be fully mastered, Meredith establishes a position that allows for these possibilities.

\section{READING NATURE WITH INQUIRY AND TENDERNESS}

Lucy/Louisa Merton/Meredith's very personal appreciation of, and interaction with, nature embraces a range of perspectives as well as modes of expression, referred to by Aunt Lucy as 'admiring', 'endeavouring to imitate', 'examining' and 'cultivating': approaches which could also be broadly identified as spiritual, aesthetic, scientific and practical. These reflect both Meredith's own interests and her desire to bring her readers to the widest possible understanding of nature's significance. Familiar, accepted concepts of her time, more typically employed to justify the domination and manipulation by colonists of new lands, are employed 'in the service of infinite and glorious creation' to promote an attitude of reverence, affection, curiosity and concern.

Meredith's appreciation of the natural world has a strong spiritual orientation - a belief that nature is a manifestation of, a pathway to, and in itself, a higher power. Her frequent references to God are the most obvious indication of her, belief in the sacredness of nature. As a manifestation of Him, as 'God's creation', as His gift to humanity, as guided by Him - the worship of nature and God are one and the same. However, although Meredith sees and worships God in nature, the spiritual aspect of nature is not restricted to God. There is no evangelising motive in Meredith's works such as there is, for example, in the publications of the Religious Tract Society. She is writing to gain converts to nature rather than converts to Jesus.

Meredith's construction of nature's spiritual dimension shifts between a devotion to nature as a manifestation of God, and a veneration of nature in, or for, itself. These contrasting ideas are held concurrently within each text, sometimes even within the same paragraph:

One might fancifully believe that the Australian colonies were discovered too soon, and that Nature - that familiar term which we so often use to spare the light or irreverent mention of the Great Divine mover and guide of all - had not completed her design; and that the dry seedy trees and juiceless herbs of Australia would, in a few more ages, have changed into kindlier and better things...

(My Home in Tasmania p.98)

Her understanding and descriptions range from Nature and God as indistinguishable, to Nature replacing God as a spiritual entity in itself; from nature as God's creation and gift to earth, to nature as an agency that brings the divine to mind; from Nature as the incarnation of Him, to Nature constructed as Her: a capricious female being and separate pantheistic entity. 
In the passage quoted above, nature and God are interchangeable terms in one breath, while in the next a female 'Nature', fickle creator of a contrary nature, takes over. The following extract from a poem, attributed to 'Thomson' and quoted to head a chapter on the aftermath of a devastating flood, allows for two opposing readings in the ambiguity of 'Great Parent', and in the use of Godlike imagery without direct reference to God; nature could either be God's force or a god-like force:

[The river] boils, and wheels, and foams, and thunders thro'!

Nature! Great Parent! whose unceasing hand

Rolls round the seasons of the changeful year, How mighty, how majestic are thy works! (Tasmanian Friends and Foes, p.70)

Similarly, nature may bring God to mind as the product of His hand:

The sight of that little rat's home set me thinking of His power and love who has created and cared for all His creatures so tenderly and wisely ...

(Tasmanian Friends and Foes, p.31)

or in a more abstract sense of inspiring religious feeling:

Above us as far as his form transcends

Man's work, however we plod;

And watching his flight, each thinker bends

A reverent mind to God.

(Grandmamma's Verse Book, p.36).

'God' provides Meredith with a familiar framework in which to think and articulate concepts of a greater power and the rightness of subjugating oneself to this power. Her references to a Christian God are generally made in the context of the more positive or benign aspects of nature: the familiar, the little things, the local, the attractive; and God is associated with creation, aptness, interconnectedness, providence, benevolence, care, and guidance.

...let us rather see

In the poor soft defenceless crab

His Maker's majesty!

... Shows the poor Hermit how to gain

A safer nook to dwell

Than any one of all his kin
Whose armour fits so well.

(Grandmamma's Verse Book, p.50)

Nature in its stranger, more awe-inspiring, challenging, and wilder aspect is less closely associated with God, and is described as if it were a separate entity (Nature rather than nature) as in the poem about the flooding river quoted above. In cases where this less comfortable aspect of nature is due to its difference, unfamiliarity, bizarreness, Nature is ,often playfully, defined as either of classical mythological origin, or as female.

It is in wilder nature, particularly, that Meredith defines a spiritual presence other than, or beyond, God. In its untouched and timeless aspect, the wilderness suggests some great spirit of/in nature that exists of itself before, after and without human awareness to bring it into being:

\author{
Majestic Temple of the Wilderness! \\ Deep, solemn, vast! \\ Hath any other mortal eye upcast \\ Glances of wonder to thy domed recesses:- \\ Or do I only \\ Worship in thy lonely \\ Aisles of primeval mightiness! \\ ('Forest Solitude', Some of My Bush Friends, \\ p.49)
}

In the 'majestic temple of the wilderness', nature's sanctity is distilled into physical form as an organic shrine. Rather than using specifically Christian terms like church or cathedral Meredith draws on the classical preChristian images of 'temple' and 'shrine' 'Reading' the blue gum forest as a work of sacred architecture - its trees, mosses and creepers forming 'domed recesses', 'verdant carpet', pillars and canopy - nature literally becomes a place of worship in its manifestation as a temple. As a site where nature and the divine are most completely at one, the primeval forest offers the human observer unmediated access to the sublime: 'No shadows thrown/'Tween holiest aspirations and their goal!'

By underpinning an understanding of nature with a spiritual sensibility, Meredith provides her readers with emotional and ethical foundations on which to build a 
respect for the environment. Linking nature with God (as His incarnation or as 'belonging' to Him), as well as putting reverential feeling into commonly understood terms, provides her with a weapon in her fight to have nature respected. In its crudest aspect, her recourse to God invokes Him as a guardian, sentinel, judge and punisher; nature is to be respected as His, and His omnipotence ensures that abuse of nature will not go unseen or unpunished:

Think you then, that GOD marketh not them who misuse and torture the creatures which He made, and said they were "very good"'?

Men, women, and children may commit, or connive at, or leave unpunished, crimes and cruelties towards the animal creation: but it is my fixed belief, that so surely as there is a hereafter, even so surely will all such wickednesses be visited upon our souls; and that not one sin of wanton cruelty against the smallest living thing will pass without its judgement, or be "forgotten before God."

(Loved, and Lost! p.13 - Meredith's emphases)

In its most philosophical aspect, her attempts to convey a sense of the transcendent power of nature, 'deep, solemn, [and] vast', promote a reverence of nature as spiritually significant to humanity, as fulfilling a nonmaterial need by offering a 'religious' encounter.

Closely allied with the sense of nature's spiritual significance is an aesthetic appreciation of $i t$. The powerful physical presence of nature is inextricably bound up with its beauty. For Meredith, natural beauty has a value, an ability to act on the observer in a way that is close to spiritual but that incorporates pleasure:

I would have her love the contemplation and study of Nature, in the widest sense of the word, so that from all created things she may draw enjoyment of the purest and most exalted kind, in observing the beauty, fitness and excellence of all God's works ...'

(Our Wild Flowers, p.67)

The aesthetic encounter with nature offers pleasure on a number of different levels: in the very act of perception, because its beautiful 'objects' (e.g. flowers, birds) and 'scenes' are a joy to behold; in the evocative power of beauty, which triggers associations and moods; and as an inspiration to creativity, in its ability to stimulate the imagination and open the mind to creative possibilities by virtue of its own 'artistry'.

Seel (1992) identifies three similar kinds of aesthetic attraction to nature: contemplative, co-responsive and imaginative. Meredith attempts to convey all three kinds of experiences in her works, as the following brief extracts illustrate.

This description of a flock of parakeets captures the sensual delight in observing the colourful chaos of their flight:

...they flit,

Like jewels, by an inner radiance lit:-

Now, hither wheeling,

Circling and soaring,-skimming-doubling back,

Crossing, they tum, and dart athwart the track

Where sunbeams stealing

In pencil-rays across that narrow glade,

Sparkle with iris-hues, on plumes o'erlaid

With lustrous colour:- changing tints that mock

All power to note them. 'Tis a flock

Of our swift Parakeets! — the brightest things

That ever lighten'd sunshine with their wings!

(Loved, and Lost! p.26)

Here nature (and her poem) offers the pleasure of an involvement in the immediacy of the experience. In the following poem, the sight of a group of orchids evokes a string of memories for the author:

Thus, times and scenes remote,

Shadows of long past hours,

I can see softly float

Across these Orchis-flowers;

Pictures of landscapes fair,

Where loving memory lingers.

Seem painted on the air,

By their quaint fantastic fingers!

('Retrospects', Some of My Bush Friends in

Tasmania, p.32,34)

Nature/flowers encapsulate the quality of a time past, prompting a pleasant flood of thoughts. 
The artistic response excited by nature is the third kind of aesthetic encounter defined by Meredith's works, one that is acted out by characters in her children's books and that is also exemplified by her works themselves. In Our Wild Flowers, writing poetry and drawing flowers are essential to Aunt Lucy's system of nature appreciation. In Loved, and Lost! the children are busy finding flowers for their mother to paint when they come across the baby parrot. Some of My Bush Friends is Meredith's 'unmediated' poetic and artistic 'labour of love in [the] service of ... our flowers, trees and insects' (she acknowledges herself as the creator, rather than substituting a character for herself). Grandmamma's Verse Book is another such poetic effort. In Tasmanian Friends and Foes Lina and Guy write about the native fauna while their mother paints the flora.

Meredith's favoured medium of aesthetic expression is poetry, which shares common ground with nature, as her expression the 'God-written Poetry of Nature' (The Romance of Nature, p.vii) suggests. The poem as an 'object' - self-contained; concise; crystallising a presence, mood or moment; concentrating beautiful words and images - is an artefact that is able to correspond with, or echo, similar qualities in nature. The "sympathy" between poetry and nature is a concept common to her time: 'In Romantic poetics, poetry is to be found not only in language but also in nature; it is not only a means of verbal expression, it is also a means of emotional communication between man and the natural world.' (Bate 1991, p.17).

Her paintings, which are chiefly of flora, are another means of capturing the beauty of nature. But whereas her poetry involves using nature as an imaginative departure point, her paintings work in the opposite way: trapping and mirroring nature's sensual pleasure in their faithfulness, in their lack of imaginative departure:

Of the Plates ... I can say nothing, but that they have been carefully engraved after my own drawings, which drawings were invariably made from NATURE. I have never been guilty of curving a stem on my paper, which 1 found growing straight in the field, or of magnifying a flower for the sake of gay effect. My models always appear to me too perfect in their beauty for me to dream of doing aught but attempt to copy, faithfully as I can, their various forms and colour: invention here must be positive error, and I anxiously strive to avoid that fault, however I may sin against the laws of picturesque effect or elegant arrangement.

(The Romance of Nature , p.xi)

The reference here to 'picturesque effect and elegant arrangement' raises another 'side' of aesthetics, namely aesthetics as a critical method, a way of 'seeing' nature and assessing natural beauty. A dominant trend at the time Meredith's views were formed, the picturesque involved a 'fashionable' way of looking at nature, by which aesthetic standards usually applied to works of art were also used to 'see' landscape (Ryan 1992).

Meredith's views developed in this cultural climate, and picturesque values are occasionally employed by her to describe and promote various natural productions as suitable elements for a landscape, as this comment on the he-oak and she-oak indicates:

Both are valuable in the landscape for their peculiar olive and brown tints and remarkable aspect ...

(Tasmanian Friends and Foes, p.78)

Delys Bird points out that the application of picturesque values was, for many colonial women, a way of demystifying the strangeness of the Australian landscape and finding a place in it for themselves. Not only was it a way of 'framing', and thereby taming, the land; it also enabled a defined relationship to their new home, by positioning them as 'cultivated settler' (Bird 1989, p.28). There are hints in the passages quoted above that an aesthetic appreciation of nature is a sign of refinement and taste, and Lina's comment, below, spells this out:

Mamma and I one day saw the drollest and prettiest subject for a picture that you can imagine. It would have been a prize for Landseer, Herring, or Harrison Weir, that wonderful bird-painter. You see we are not without appreciation of art, even in our remote hermitage-home.

(Tasmanian Friends and Foes, p. 106 - on seeing 
a lamb attack an eagle)

It is clear that Meredith saw herself as a 'civilising agent', a 'cultivated settler' who, by bringing culture to the 'sadly prosaic' colonists, could refine their attitude to their environment, enabling them to recognise it as beautiful, and see it in terms other than economic.

Meredith's aesthetic response to, and representation of, nature heightens her readers' awareness of the 'vivid pleasure' that the natural world can offer: nature should be valued and cared for because of the unique and complex joy experienced in its presence. 'Aesthetically valuable nature is not good because it can be used for other purposes, it is a place where it is good to be.' (Seel 1992, p.78 my italics)

Meredith's spiritual and aesthetic views of nature and her scientific interest in it share some common ground. Describing, collecting, classifying, cataloguing, labelling, naming, encourage a view of nature as composed of individual aspects which all belong to a whole. Science in this way reflects and reinforces Meredith's spiritual conception of nature as a 'divine plan', where 'each shell, each crawling insect holds a rank/Important in the plan of Him who framed/This scale of beings' (Tasmanian Friends and Foes, p.23, attributed to Stillingfest).

Meredith's insistence on the importance of scientific accuracy can be as much a submission to the beauty and perfection of the natural object as it is a push for factual precision (to requote from above: 'My models always appear to me too perfect in their beauty for me to dream of doing aught but attempt to copy, faithfully as I can, their various forms and colour'). And conversely, her factual descriptions of flora and fauna, while detailing various physical characteristics in a fairly objective way, also contain a strong aesthetic appreciation of their subjects:

After the beautiful long white stamens have withered and fallen, the calyx hardens and browns into a woody seed-vessel, very ornamental also, as are many of those borne by Australian trees and shrubs.

(Some of My Bush Friends, p.54)

Like many educated middle-class women of her time,
Meredith had made extensive botanical studies (as the encyclopaedic Our Wild Flowers testifies), and was familiar with Latin, the Linnean classification system and scientific methods of specimen collection. She was also knowledgeable in geology, conchology, ornithology and zoology, as evidenced by (for example) the 'educational asides' on these subjects that occur in a number of her works. "Scientific friends of Mamma's" (Tasmanian Friends and Foes, p.37) feature in a number of works, indicating Meredith's participation in the exchange of information, specimens and 'discoveries' with the very active and wide-flung network of amateur and professional botanists and naturalists that extended across Tasmania, mainland Australia and England. She corresponded with such 'eminent professors' as Baron Ferdinand von Mueller, who named a species after her (Some of My Bush Friends, p.5). Her scientific studies of Australian flora and fauna had intellectual credibility and some small recognition in the scientific community.

While Meredith's spiritual and aesthetic viewpoints remain fairly consistent throughout her works, her scientific interests show a change from (in her English works) treating science as very closely allied with culture and an aesthetic viewpoint, to a more objective approach to nature. Her Australian books suggest a difficulty or reluctance to blend the scientific and aesthetic/cultural, although the different views are still part of the total work. Loved, and Lost! is divided into three parts - a 'greeting', poem, and explanatory notes, with the latter containing the factual 'scientific' information. Some of My Bush Friends and Grandmamma's Verse Book also employ the same device to include more strictly factual information. In Tasmania Friends and Foes, the separation is still evident in the three distinct narrative strands, of which Lina and Guy's 'gossips' (or 'scientific articles' as Guy ironically calls them) contain the bulk of the factual observations of native fauna. In this book the scientific component is also highlighted by Meredith's index.

The 'firming' of Meredith's scientific interests indicates her awareness that she is covering new ground:

In old countries, where every change of season, every successively opening flower, and every insect that flutters the frailest wing in the sunshine, 
has attracted the study of naturalists and philosophers for centuries, we can always refer to books for information respecting all that interests us, or excites our curiosity. But here, if we would learn from Nature, we must strive to read her own untranslated history, and no one who has not tried can tell how pleasant a book it is.

(My Home in Tasmania, p.210)

Whereas in England there was 'no room for her (amateur) pen' other than in a creative capacity, in Australia her personal observations of an unfamiliar and only partially defined nature were of interest and value in themselves. By assigning 'scientific information' to a separate section of her works, she is able to preserve the factual integrity of her observations, and also serve her creative interests: the flight of fancy means more if the point of departure is known.

Meredith's well-established commitment to close personal observation is the backbone of her scientific approach. She sees it as the only means of ensuring accuracy, or Truth: 'the anecdotes of birds and animals are facts, set down simply from our own experience' (Tasmanian Friends and Foes, p.3); 'I shall not repeat to you anything that we do not ourselves know to be absolutely true. Pray remember that.' (p.106- her italics). Personal observation entails an active involvement on a level achievable by all, which is beneficial for the individual, for nature and for science. Any active involvement, no matter how amateurish, has the potential to add to existing knowledge. Mrs. Merton impresses its importance upon her young 'natural scientists' in Tasmanian Friends and Foes:

'I remember an old friend of mine in England, a good naturalist,' said Mrs. Merton, 'asking me to write descriptions of anything and everything ! saw out here; and my natural remark was, that I should not know what had been told before, nor what was most useful to be observed. His reply was - "Observe everything, and describe everything. Ninety-nine things have probably been better done before, but the hundredth may be a welcome addition to general information." " (p.69)
Meredith's scientific view of nature provided her readers with another set of approaches with which to establish personal connections with the natural world. Close observation requires an active 'hands on' experiencing of the environment, a situation most conducive to increasing the observer's sensitivity towards nature. 'Reading nature's untranslated history' scientifically involves finding a place for it in the existing systems of defining and ordering the natural world; of seeing continuity \& similarities; of conceiving of Australian nature as 'part of rather than 'Other'. And it is an approach which results in a kind of ownership: where the participant must collect - either physically by gathering and preserving specimens (the 'tin box' features prominently in several works), or by recording (sketching or writing), or simply by memory (adding each new 'find' to a mental collection). ln all cases, the participants are expanding their own personal context in which to put things, and broadening their understanding of their natural world.

Meredith clearly associates science with adding to the fund of human knowledge, and knowledge with the betterment of humankind. In a family discussion on the cruelty of caging birds, Mr. Merton speaks for his author when he says,

...I have more faith in the effect of rational, wholesome education for the masses of the people, than in any special law-making on the subject.

(Tasmanian Friends and Foes, p.38)

However, there are limits to what she will approve of in the name of scientific investigation. Criticisms of the thoughtlessness and destruction committed in the name of science abound, together with the occasional dig at the male expert:

I never heard of anyone attempting to tame them [platypus], except Dr. Bennett of Sydney, the great naturalist whose account of several he tried to keep alive is very curious and interesting but all died very soon; and it is sad to read of the numbers of these rare and hamless creatures killed to assist scientific investigations into their forms and habits.

(Tasmanian Friends and Foes, p.57) 
Meredith's effort to instil a love and respect for nature is the logic behind all her views, from the most philosophical/ spiritual to the most practical level. She is not interested in natural science as a specialised intellectual activity divorced from the reality of the living things it studies. Her scientific interests are mediated by very practical concems, and the well-being of her subjects is her primary consideration.

When Aunt Lucy tells Agnes that 'it is very seldom that I pull a flower to bits, to discover its class and order' (Our Wild Flowers, p.v), the rather destructive-sounding description expresses Meredith's preference for a 'low impact' study of nature. Aunt Lucy and Agnes are models for this approach: '.. suppose we ... try how much we can learn about [wild flowers] by merely walking, looking, and talking.' (p.4). The very presence of humans in a natural setting involves potential damage:

But keep to the path-do not roam in the grass,

For our feet there do mischief wherever they pass,

And he must be a heartless and ill-natured elf

Who would injure another to gratify self.

('A Summer Ramble', Our Wild Flowers, p. 181)

'Rules' about how to respect and care for nature are liberally distributed through her works.

Practical advice - on animals and plant care, on how to conduct oneself in nature, on how to carry out responsible scientific inquiry - is liberally distributed throughout her works (see Part III for detailed examples).

All Meredith's characters live in close, 'hands on' contact with the natural world, constantly interacting with it and learning to know it intimately: cultivating gardens (often featuring botanical collections of Australian plants), tending to animals in need, befriending the local fauna and at times sharing their houses with it, conducting nature rambles and explorations. The natural world is not relegated to picturesque or exotic backdrop; her characters live in and with a vibrant, teeming, independently existing nature.

Practical concerns are the grounding factors of Meredith's works, providing a firm foundation for what could have been merely pious, sentimental, or fashionable, by emphasising and demonstrating the reality of her subject.

\section{CREATING A HABIT OF MIND}

... I have one eamest purpose at heart - the desire to devote the best help which I am capable of bringing to the good work of showing to all, but especially to the young, how full of healthy, refining, vivid pleasure is that habit of mind which to ardent, reverent admiration of the Creator's works unites tender care for the comfort and happiness of our dumb friends and companions.

(Tasmanian Friends and Foes, p.5)

Meredith perceives an intimate bond between childhood and nature, a relationship of connectedness and empathy, which provides her with the foundation for the right kind of relationship with nature. Her young child in nature radiates a sense of freedom, excitement, discovery, energy and delight that suggest an unparalleled purity of experience and an instinctual affinity with nature. However, this early relationship is threatened as the child grows older.

The young child's unmediated sensual apprehension of nature is modified by an increasing objectivity, an inevitable part of growing up. In some of her child characters, this growing objectivity enables the development of a corresponding intellectual pleasure in nature. Lina, the oldest Merton daughter in Tasmanian Friends and Foes, for example, retains her early love of animals - now not only a source of physical enjoyment but also the source of an emerging creative engagement with the natural world. She recreates her pleasure in nature through her narratives about animals of her acquaintance in her letters to her English cousin. Lina is a model for the kind of attitude Meredith seeks to foster in her reader.

On the other hand the older Bexley children (Tasmanian Friends and Foes), family friends of the Mertons, have lost touch with nature. They are examples of an overly refined upbringing that has not fostered and cultivated their connection with their natural surroundings, and their wealth is represented as a contributing factor. Their insensitivity to their natural surroundings contrasts unfavourably with Lina's considerate appreciation: her 
care not to pick more than one of each flower for her collection prompts Kate's pettish response: 'La! ... as if it mattered. They're no good.' (p.137). Older brother Harry is amusingly clueless in the face of Lina's reverence:

'Now then, look alive! Sharp's the word, and down you go!' cried Harry, not quite comprehending Lina's silent, delighted pause of rapt admiration at so new and glorious a scene...' (p.138)

The Bexley children (apart from the youngest) have been 'spoilt'; in losing touch with nature they are left shallow and dissatisfied.

The example of the Bexleys serves to illustrate Meredith's belief that children need to be actively and consistently educated in appreciating nature to keep their rapport with it alive, and this is supported by both the didacticism and the example-setting evident in her writings. Unless children are taught and shown how to love and respect their natural environment, their early affinity with nature is unlikely to develop, as Mr. Merton reminds them:

'Had you all been reared in a home where wanton cruelties were continually practised without condemnation, even you would not be as rightly sensitive to animal suffering as you now are, after having always before you my own watchfulness against every kind of inthumanity to God's dumb creatures, and your mother's tender care for all helplessness and suffering.'

(Tasmanian Friends and Foes, p.38)

His comment not only echoes Meredith's commitment to encouraging the child in a 'right relationship with nature'; it also indicates the gender-mediated relationship to nature to which the child is heir. Mr. Merton's 'watchfulness against every kind of inhumanity to God's dumb creatures', and Mrs. Merton's 'tender care for all heIplessness and suffering' (my emphasis), define the male as manager and the female as nurturer.

With the exception of the apathetic older Bexley girls, the female view of nature is a fairly unified one in Meredith's works. All her girls seem to be models, at various stages of development, of a feminine ideal: nurturing, artistic, intellectually active. The descriptions written in Meredith's 'own voice' are so similar to those of her girl narrator, Lina, for example, that a common viewpoint can be assumed. The loving observations, the fixing on endearingly comical habits, which encourage the reader to discover and enjoy the character of each animal, are central to both.

However, while the sanctioned viewpoint in all Meredith's books is most closely associated with females, it is partly shared by a small number of enlightened males, most notably Mr. Merton and (at his best) Guy, in Tasmanian Friends and Foes, and Meredith's son in Loved, and Lost! Some of the boys in poems from Grandmamma's Verse Book are also models of a kinder attitude to nature. Unlike most males of the time, they are opposed to the English mode of hunting as a sport. Guy, for example, is most relieved to find evidence that his fishing expeditions are not the exercises in cruelty that he suspected them to be: 'I am very glad to have such a proof that the poor fish are so much less sensitive than I feared.'(p.226). They also have an appreciation of natural beauty; Guy Merton and Meredith's son, for example, find flowers for their mothers and enthusiastically contribute their opinions on how the ensuing artwork should proceed.

However, their 'masculinity' will out on occasions. Although priority is given to the female view of nature, Meredith does allow space for the male reader in the various depictions of caring, yet still conventionally robust and rough, boys. Meredith's sons in 'A Home Picture' are far from gentle in their bush ramble, al though they are still aware enough of the surrounding flora to be stopped in full flight by it:
Ah! a grey bandicoot ran by! And here
Through thickets crushing,
Plunge our bold boys, with eager dogs, on pushing
In noisy chase, -hallooing, barking, rushing
Down to the river: - when the rash career
Is checked all suddenly, and 'Mother! see!
'A garden of wild raspberries!' ...
(Some of My Bush Friends, p.103)

A more aggressive, commanding conduct in, and to, nature is attributed to an essential 'maleness' by Meredith. However, while it is the male role to assert man's 
dominance over nature, by virtue of natural predisposition, 'war' should only be made 'sometimes' and only when 'obliged':

'Mamma and I were always so sorry to have opossums killed, that Papa took us to see the dreadful havoc our favourites made, to prove to us that he was obliged to make war on them sometimes.'

(Tasmanian Friends and Foes, p.34)

Although the more manipulative male relationship to the environment is reluctantly given its place as an occasional necessary evil, the nurturing accepting female role is always the first approach.

The less pleasant role of occasionally 'making war' on nature that is assigned to the male, is echoed by the narrative device of assigning the more 'violent' subjects to a male narrator. Meredith's young male narrator exposes the philosophical difficulties presented by the crueller aspects of nature: those animals that display open hostility, with which humans are unable to establish a rapport or live in harmony. Meredith, while glorifying, or at least respecting, the wild in landscape and the elements, is very ambivalent towards the 'savage' native cat that 'grips [her poultry] by the throat and sucks the blood of as many as it can seize.' (Loved, and Lost! p.92). It is worth noting, though, her addition of the comment: 'English cats gone wild are even more mischievous' which indicates that her enmity is not reserved for native species. Her male narrator enables her to give voice to her hostile feelings and simultaneously critique any extremes of aggression; to articulate her inability to reconcile animal 'hostility' with conservation.

When Lina suggests writing a collection of anecdotes about the animals the Mertons have encountered in Tasmania, Guy offers to 'do the Tigers and Devils and native Cats... [t] they're more in my line than yours' (p.2l), while the 'harmless' animals are deemed more appropriate subject matter for a girl. His dramatic language and exaggerated retelling are in marked contrast to Lina's gentle affection. He delivers his 'Gossip' with all the dash and verve of an adventure story, full of boyish overenthusiasm to do battle on behalf of the defenceless:
'We don't show the brutes any mercy; they do too much mischief. The young lambs stand no chance at all with them. So we hunt them down, or set traps, or dig pitfalls - any and every way we can destroy them we do. Why, one winter, some years ago, one of Papa's shepherds caught nearly one hundred and fifty!'

(Tasmanian Friends and Foes, p 64)

The punitive response to savage nature (as represented by Tasmanian devils) in this extract is only partly justified by the devils' 'cruelty' to other animals. The thoroughness of the animals' eradication is in marked contrast to the rest of Meredith's text; underlining the immaturity that is apparent in Guy's highly-coloured narrative, and hinting at the ignorance behind such a campaign of extermination in assigning the deed to a presumably uneducated and unenlightened shepherd rather than Papa. Guy's 'gossip', while illustrating the need to 'manage' nature, reveals the danger of excess inherent in male naivety and ignorance, and indicates the importance of privileging the ferninine viewpoint.

Under the right influence, even someone as recalcitrant as Harry Bexley - who abandons and loses his sisters and young guest in an unexplored fern gully 'for the brutal pleasure of chasing [a] kangaroo' (p.145) - is capable of reform. After some time with Lina, the confirmed hunter is made to remark: 'It's a great pity everything's being killed off at such a rate.' (p.157)

For the benefit of the 'Bexley's' amongst her readership, those less likely to be sensitive to the subtler aspects of her case, Meredith employs a didactic approach, spelling out 'rules' about how to respect and care for nature. I would like to close this discussion of her pioneering conservationism with a brief survey of this most overt aspect of her fight for nature. Her 'rules' make fascinating reading because they are astonishingly close to contemporary concerns and attitudes towards the environment, animal welfare and conservation.

Careful and considerate observation is encouraged, and all forms of destruction and cruelty are sternly criticised. Collecting or sampling, for example, should be done in moderation and with a specific purpose: 
'I have only picked one of each kind to press and keep, for Mama has always taught us not to gather flowers in waste. I have seen her quite unhappy when she has observed people plucking quantities of flowers only to throw away again.'

(Tasmanian Friends and Foes, p.137)

The prestige of owning the rare is not seen as a worthy reason for collecting, as yet another veiled criticism (and ridiculing) of a 'scientist' indicates:

'After living with us for some time, our tiny pet was carried off in great triumph by a scientific friend of Mamma's, who took it with him on his return to England, but the little mouse died before arriving there.'

(Tasmanian Friends and Foes, p.37)

Specimens temporarily captured to be studied must be handled with due care, so that 'scientific inquiry' does not result in their demise:

'Now we will put our very curious friend on this white paper, and place the shade over it, leaving the glass a little raised at one side to admit air.' (Tasmanian Friends and Foes, p.23)

The natural environment of an animal is its rightful place:

'If we could put it back into the nest, That, for the bird, were wisest, kindest, best; For all our care, and all the daintiest food To the poor pretty one are not so good As the familiar shelter of the nest, And the warm softness of its mother's breast. (Loved, \& Lost! p.40)

Removing an animal from its natural home is only condoned if the alternative is harmful, if, for example, it is not 'able to provide for its own wants (Loved, \& Lost! p.18). Such animals must be given 'perfect freedom' to leave when they are able. Loved, and Lost! is based upon this premise.

Taming animals as pets is presented as, at the very least, a risky business: '... even with the greatest care, such birds are always shortlived, and pets generally come to an untimely end.' (Loved, \& Lost! p.14). On a more philosophical level, domesticating them robs them of their character, as in the case of 'Poor Cockie', the 'impudent', 'mischievous', 'attentive' trained cockatoo, who is also 'a desolate Cockatoo' because he is not free to fly and find a mate, but must endlessly play out his semi-human performance for the amusement of his owners (Grandmamma's Verse Book, p.47).

Caging pets is vehemently condemned, and Meredith employs her most thundering preacher's voice to discourage the practice, as we saw in an example quoted above in the discussion on her religious view of nature. Also strongly disapproved of is hunting for sport, as the violent cutting down of joyous life in 'Wattle Birds in Gum Trees' drives home:

'Coruckity-ruck! Coruckity-run!

What blithe merry creatures are we!'

As she spoke, came the flash and report of a gun -

Fell — bleeding and dead - her bright plumage

tom,

Her grace and her beauty all o'er;

But the sportsman said, 'Capital shooting this mom,

I've bagged in one hour full a score.'

(Grandmamma's Verse Book, p.23-4)

There is a sense of urgency in Meredith's messages of protection and conservation. Along with her 'rules' are frequent references to the rapid deterioration and destruction of a recently 'pristine' environment:

... judging from the merciless quantities which are brought down from the mountain into Hobarton, the trees are in danger of extermination. (Some of My Bush Friends, p.47)

The panting engine's steam Breathes hotly on before:

But from not glen or grove at a'

Shines out at me one Waratah!

(Grandmamma's Verse Book, p.38)

'...the poor Foresters have been hunted down in hundreds and thousands, and killed so cruelly, that Papa thinks they will be quite gone before long.' (Tasmanian Friends and Foes, p.16) 
In Meredith's final children's book, Lina concludes her letters for her English cousin about Australian fauna with this remark: 'You had better come to us for a year's visit before all the native things are killed ...' (Tasmanian Friends and Foes, p. 129) It is a pessimistic note on which to finish, but one that stresses the imperative of a widespread change of attitude. Reverence, aesthetic appreciation, knowledge and inquiry, and a practicallybased compassion and consideration: in combination, these constituted the 'habit of mind' that was Meredith's hope, and that she strove to write into her reader.

It is interesting that, 150 odd years after Meredith made it her 'earnest purpose' to inculcate a love and respect for nature by using all the means at her disposal, some of these means are being revisited by contemporary environmentalists and eco-critics. In particular, the amateur interest in natural history, aesthetic responses to nature, and the Romantic conception of nature as being of intrinsic value, are being re-evaluated as a means of fostering a more ethical relationship to the environment. Her political activism via her parliamentarian husband, so unusual for the time that he was almost laughed out of the House, is today accepted practice. Despite the now rather archaic tone and literary modes of her books there is still an immediacy to her work, in the shared concerns of our 'environmentally conscious' contemporary society and a 'sensitive colonist'. In Meredith's work we can rediscover a past where taking possession of the land meant something other than exploitation, where ownership also involved taking responsibility.

\section{REFERENCES}

Bate, Jonathan (1991) Romantic Ecology - Wordsworth and the Environmental Tradition. London, Routledge.

Bird, Delys (1989)' Gender and landscape - Australian colonial women writers', New Literatures Review 18 , 20-36.

Ellis, Vivienne (1979) Louisa Anne Meredith - A Tigress in Exile. Sandy Bay, Blubber Head Press.

Greer, Germaine (1995) Slipshod Sibyls: Recognition, Rejection and the Woman Poet. London, VikingPenguin.
Keller, Evelyn (1985) Reflections on Gender and Science. New Haven, Yale University Press.

Meredith, Louisa Anne (1878) Grandmamma's Verse Book for Young Australia. Printed for the author by W. Fletcher.

Meredith, Louisa Anne (1860) Loved, and Lost! The True Story of a Short Life. London, Day and Son.

Meredith, Louisa Anne (1852) My Home in Tasmania, During a Residence of Nine Years. London, John Murray.

Meredith, Louisa Anne (1844) Notes and Sketches of New South Wales, During a Residence in that Colony from 1839 to 1841. London, John Murray.

Meredith, Louisa Anne (1839) Our Wild Flowers Familiarly Described and Illustrated. London, Charles Tilt.

Meredith, Louisa Anne (1836) The Romance of Nature, or The Flower Seasons Illustrated. London, Charles Tilt.

Meredith, Louisa Anne (1860)Some of My Bush Friends in Tasmania: Native Flowers, Berries, and Insects Drawn from Life, Illustrated in Verse and Briefly Described. London, Day and Son.

Meredith, Louisa Anne (1880) Tasmanian Friends and Foes, Feathered, Furred and Finned. A Family Chronicle of Country Life, Natural History, and Veritable Adventure. London, Marcus Ward \& Co. Also published by Walch \& Sons, Hobart Town, Waich Brothers \& Birchall, Launceston.

Pepper, David (1984) The Roors of Modern Environmentalism. New Hampshire, Croon Helm.

Ryan, Simon (1992) 'Exploring aesthetics: the picturesque appropriation of land in journals of Australian exploration', Australion Literary Studies 14, 3, 282293.

Seel, Martin (1992) 'Aesthetic arguments in the ethics of nature', Thesis $11,32,76-89$.

Sheldrake, Rupert (1990) The Rebirth of Nature. London, Century. 
Smith, Bernard (1960) European Vision and the South Pacific. London, Oxford University Press.

\section{$\rightarrow$ P.:EK-}

\section{BIOGRAPHICAL NOTE}

Kordula Dunscombe has completed a Graduate Diploma in Children's Literature, and has worked as a Research Assistant on a project on nineteenth-century Australian children's literature at Deakin University. This article arises from her research work.

$\rightarrow 20$ :EK 